\title{
Viabilidade do emprego de cinza de casca de arroz natural em concreto estrutural. Parte I: propriedades mecânicas e microestrutura
}

The feasibility of using natural rice husk ash in structural concrete. Part I: mechanical properties and microstructure

\section{Geraldo Cechella Isaia \\ Antonio Luiz Guerra Gastaldini \\ Leticia Meira \\ Marcelo Duart \\ Raul Zerbino}

Geraldo Cechella Isaia Departamento de Estruturas e Construção Civil, Centro de Tecnologia Universidade Federal de Santa RS $509 \mathrm{Km} 9$ Cidade Universitária, Camobi Santa Maria - RS - Brasil CEP $97119-900$

Tel.: (55) 220-8144

E-mail: gisaia@terra.com.br

Antônio Luiz Guerra

Gastaldini

Departamento de Estruturas e Construção Civil, Centro de Tecnologia Universidade Federal de Santa

E-mail: gastaldini@pq.cnpq.br

Leticia Meira Programa de Pós-Graduação em Engenharia Civil Universidade Federal de Santa Maria engleticiameira@yahoo.com.br

Marcelo Duart Programa de Pós-Graduação em
Engenharia Civil
Universidade Federal de Santa Programa de Pós-Graduação em
Engenharia Civil
Universidade Federal de Santa Maria E-mail: marceloduart@yahoo.com.br

Raul Zerbino Laboratorio de Entrenamiento Multidisciplinario para la Investigación Tecnológica Avenida 52 entre 121 e $122, \mathrm{~s} / \mathrm{n}^{\circ}$ La Plata - Província de Buenos Aires Argentina

E-mail: zerbino@unlp.edu.ar

Recebido em 15/07/09 Aceito em 06/11/09

\section{Resumo}

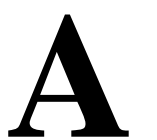

casca de arroz, para ser utilizada em concreto estrutural, necessita de queima com temperatura controlada e de moagem prévia para lhe conferir maior reatividade pozolânica. Este trabalho discute o emprego da cinza de casca de arroz (CCA) natural e residual, queimada sem controle de temperatura e sem moagem, de forma a simplificar o processamento da CCA e ampliar seu uso em concretos convencionais, em locais próximos onde é produzido, Estudou-se a sequência de colocação e o tempo de mistura dos materiais na betoneira, para obtenção do melhor desempenho da automoagem no tambor. Foram testadas misturas de concreto de referência com cimento Portland e com $15 \%$ e $25 \%$ de substituição de cimento, em massa, por CCA natural e moída. Foram realizados ensaios de resistência à compressão axial, tração por compressão diametral, módulo de elasticidade, retração total, porosimetria por intrusão de mercúrio, água quimicamente combinada e MEV. A análise dos resultados revela a viabilidade da substituição de $15 \%$ de cimento por CCA natural, com perda não significativa de resistência à tração e módulo de elasticidade a 28 dias, com recuperação total a 91 dias, para concretos com resistências à compressão entre 25 $\mathrm{MPa}$ e $40 \mathrm{MPa}$.

Palavras-chave: Cinza. Casca de arroz. Propriedades mecânicas. Microestrutura.

\section{Abstract}

Rice husk needs to be burnt at controlled temperatures and be ground to increase its pozzolanic reactivity, in order to be used in structural concrete. This article examines the use of natural and residual rice husk ash (RHA) burnt without temperature control and without grinding, aiming to simplify the processing of rice husk ash and increase its use in conventional concretes, closed to the location where RHA is produced. This study investigated the order in which materials are added to the mixture and at mixing times so as to obtain better self-grinding performance inside of the drum. Reference concrete mixtures with Portland cement and with $15 \%$ and $25 \%$ cement mass replacement by natural and ground RHA were tested. The following tests were performed: axial compression strength, tensile strength by diametral compression, elasticity modulus determination, total shrinkage, mercury intrusion porosimetry, chemically combined water and SEM. The analysis of the results indicates the feasibility of replacing $15 \%$ cement by natural RHA, without significant loss of tensile strength and elasticity modulus at 28 days, with total recovery at 91 days for concretes with compression strength between 25 and $40 \mathrm{MPa}$.

Keywords: Ash. Rice husk. Mechanical properties. Microstructure. 


\section{Introdução}

Entre as pozolanas para uso em concreto estrutural, a cinza volante, a cinza de casca de arroz e, recentemente, a cinza do bagaço de cana destacamse por serem subprodutos resultantes da produção de energia para fins industriais. Para melhorar as propriedades das cinzas de origem vegetal misturadas ao concreto, relata a experiência atual que devem ser previamente queimadas, se possível com controle de temperatura, e moídas com o intuito de aumentar sua finura e, assim, incrementar o desempenho das propriedades mecânicas e da durabilidade.

Por questões de sustentabilidade, a grande quantidade de cinza de casca de arroz produzida atualmente deve ser aproveitada especialmente em concreto, maior consumidor potencial desse subproduto. Entretanto, a falta de disponibilidade no mercado de CCA com características consideradas adequadas para tal uso resulta em grandes quantidades depositadas a céu aberto, potencializando a poluição ambiental de solos e mananciais aquíferos. Para Prudêncio, Santos e Dafico (2003), o não aproveitamento da CCA, descartada em condições não sustentáveis, é um destino que não pode ser aceito pela sociedade, razão pela quais inúmeras pesquisas foram realizadas nos últimos dois decênios sobre seu emprego em concreto estrutural.

A maioria das pesquisas sobre o uso de CCA em concreto aponta como condição para seu emprego com fins estruturais que deva possuir alta reatividade química, para que as reações pozolânicas se processem em condições mais favoráveis e potencializem o desempenho requerido para o concreto (FENG, 2003; MEHTA, 1994). Alguns pesquisadores são da opinião de que a CCA residual produzida sem temperatura controlada e de menor finura também pode ser utilizada em estruturas de concreto, porque pode apresentar características de qualidade suficiente para bom desempenho mecânico e no que se refere à durabilidade (GUEDERT, 1989; ISAIA, 1995; REGO, 2004). Resultados significativos obtidos com a CCA residual podem ser creditados não só ao efeito pozolânico como também aos efeitos físicos de dispersão e nucleação das partículas de cimento em razão do potencial zeta, e de tamponamento dos poros (ISAIA; GASTALDINI; MORAES, 2003; SENSALE, 2006).

A maioria dos engenhos de arroz brasileiros não tem interesse no beneficiamento da casca, descartando a cinza como resíduo e, na maioria das vezes, contra as normas ambientais, o que ocasiona poluição ambiental. Empresas de outros segmentos industriais não têm mostrado interesse no beneficiamento da CCA, seja pelo investimento em equipamentos, seja pelo consumo de energia agregado ao produto final, o que aumenta seu custo.

Um procedimento que pode ser empregado para aumentar o uso da CCA residual em concreto estrutural, dando-lhe um destino mais sustentável, seria sua utilização in natura, no estado como é obtida após a queima, sem moagem. Adicionada diretamente na betoneira, seria automoída com os demais agregados dentro do tambor, resultando na cominuição de suas dimensões, o que reproduziria em parte, o processo de moagem prévia da CCA, tradicionalmente utilizado nas pesquisas vigentes. Com o uso dessa estratégia, seria aumentado seu potencial de utilização, especialmente em obras de pequeno e médio portes, em regiões próximo às zonas produtoras de $\mathrm{CCA}$, situação em que geralmente o concreto é misturado no próprio canteiro. Assim, seria minimizado o transporte desse material de baixa densidade $\left(\approx 120 \mathrm{~kg} / \mathrm{m}^{3}\right)$, não seria consumida energia para o beneficiamento desse resíduo e seria dado destino adequadamente sustentável pela diminuição do consumo de clínquer no concreto, com todas as consequências benéficas decorrentes relacionadas ao meio ambiente.

Para contribuir com o uso dessa nova modalidade de CCA residual em concreto estrutural, sem moagem prévia, este trabalho apresenta os resultados de pesquisa coordenada pelo Grupo de Estudos e Pesquisas em Concreto (Gepecon) da Universidade Federal de Santa Maria, Brasil. Foram realizados estudos de concreto fresco para determinar a melhor sequência de colocação dos materiais na betoneira e o tempo de mistura para maximizar as propriedades relacionadas à resistência mecânica e à durabilidade. É apresentada neste trabalho a primeira parte dos resultados dos ensaios mecânicos, de deformação e de microestrutura de misturas de concreto com CCA residual natural (CCAN) e, também, com moagem prévia (CCAM), para comparar seus desempenhos e averiguar, assim, a viabilidade do uso da cinza natural em concreto estrutural.

\section{Materiais e Métodos}

\section{Estudo prévio com CCA natural e moída}

Foram amostradas CCAs de 17 engenhos de arroz de Santa Maria, RS, recolhidas no estado em que saíram das fornalhas, sem controle de temperatura. Realizaram-se ensaios de resistência à compressão 
de argamassa conforme a NBR 7215 (ABNT, 1996), com a CCA natural, sem beneficiamento, e com a CCA moída em moinho de bolas metálicas por $1 \mathrm{~h}$, com teores de substituição de cimento entre $15 \%$ e $30 \%$ em massa. Adotou-se a resistência à compressão dos corpos de prova (CPs) como parâmetro de comparação. Os melhores resultados foram das CCANs das indústrias Trevo, Induber e Marzari. Nesta última, o teor de carbono era muito elevado (20\%), razão pela qual foi descartada. Novo ensaio com as duas primeiras revelou que a CCAN do engenho Induber apresentou resistência à compressão mais representativa em relação às demais, sendo escolhida para realizar os ensaios das etapas subsequentes. Observou-se que o teor de $30 \%$ de substituição de cimento por CCAN apresentou queda de resistência importante, mais de $30 \%$ em relação ao teor de $15 \%$, razão pela qual foi reduzido para $25 \%$ nos ensaios posteriores. A Figura 1 apresenta CCAN, conforme amostrada no engenho de arroz, e CCAM de laboratório.

A seguir estudou-se a sequência de colocação dos materiais na betoneira e o tempo de mistura com concreto de relação $\mathrm{a} / \mathrm{mc}=0,55$ (valor central da pesquisa), com o mesmo cimento da etapa anterior, e substituição de $15 \%$ e $25 \%$ de sua massa por
CCAN e CCAM. Empregou-se betoneira de eixo inclinado com cuba de $120 \mathrm{dm}^{3}$ e capacidade de mistura de $40 \mathrm{dm}^{3}$. O parâmetro de controle foi a resistência à compressão axial de $\mathrm{CP}$ de $10 \mathrm{~cm} \mathrm{x}$ $20 \mathrm{~cm}$, a 28 dias de idade $\left(\mathrm{f}_{\mathrm{c} 28}\right)$, e os teores de material retido nas $\# 0,075 \mathrm{~mm}$ e \#0,044 $\mathrm{mm}$ por peneiração úmida, seguida por peneiração seca, previamente retirados da argamassa do concreto fresco. Sendo todos os materiais do mesmo lote, a única variável significante foi a finura das CCAN, que forneceu, assim, valor comparativo sobre a influência do tempo de intermoagem dos materiais na betoneira, combinada com os resultados de $\mathrm{f}_{\mathrm{c} 28}$. Devido à inexistência de dados da literatura, após muitas simulações experimentais foram adotadas as seguintes ordenações de colocação dos materiais no tambor e os tempos de mistura, que produziram as melhores resistências à compressão axial e menores teores de material retido no ensaio de peneiramento:

(a) misturas CCAN: (britas $+\mathrm{CCAN}=2^{\prime}$ ), (água + aditivo $=2^{\prime}$ ) , cimento $=2$ ' e areias $=9$ '. Tempo total $=15^{\prime}$; e

(b) misturas CCAM: (britas + água $=2^{\prime}$ ), cimento $=2$ ', aditivo $=2$ ', $\mathrm{CCAM}=2$ ' e areias $=2$ '.

Tempo total $=10^{\prime}$.

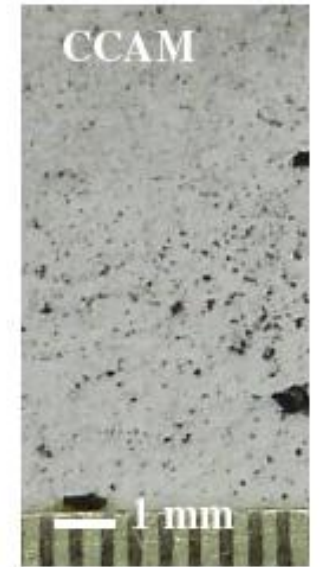

(a) CCAM, moída por

$1 \mathrm{~h}$ em moinho de bolas

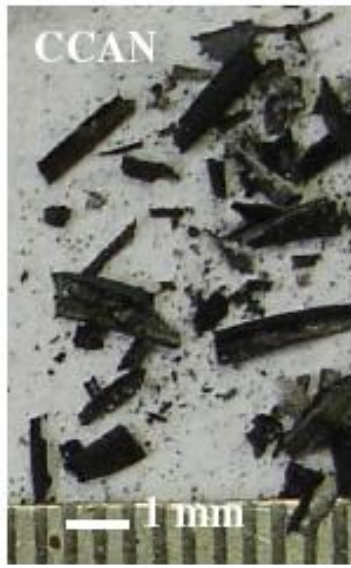

(b) CCAN, natural, sem moagem

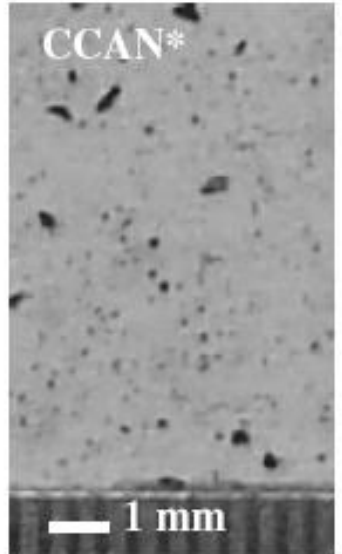

(c) $\mathrm{CCAN}^{*}$, natural e moída por $10 \mathrm{~min}$ na betoneira

Figura 1 - Cinza natural (CCAN) e moída (CCAM) 


\section{Características dos materiais cimentícios}

Utilizou-se cimento Portland CPII F - 32, conforme a NBR 11578 (ABNT, 1991), CCAN, amostrada no engenho de arroz Induber, e a mesma CCA moída em laboratório, conforme 2.1. A cominuição da CCAN na betoneira durante a mistura do concreto foi estudada pela intermoagem dos componentes a seco (sem cimento), com as mesmas quantidades das misturas dos materiais dentro do tambor, por $15 \mathrm{~min}$, respeitando-se a composição dos traços e o teor de $15 \%$ e $25 \%$ de substituição de cimento por CCA. A Tabela 1 apresenta os resultados dos ensaios das características físicas e químicas dos materiais cimentícios, e a Figura 2, as curvas granulométricas obtidas em granulômetro a laser.

A soma de $\mathrm{SiO}_{2}+\mathrm{Al}_{2} \mathrm{O}_{3}+\mathrm{Fe}_{2} \mathrm{O}_{3}>50 \%$ e o teor de $\mathrm{SO}_{3}<3,0 \%$ e de $\mathrm{Na}_{2} \mathrm{O}<1,5 \%$ contemplam os requisitos da norma NBR 12653 (ABNT, 1992) para material pozolânico da classe $\mathrm{E}$. O teor relativamente alto de potássio poderia ser uma das causas da maior cristalização das partículas amorfas, na formação de cristobalita, conforme a Figura 4.
A Tabela 1 mostra que a CCAN apresentou massa específica $48 \%$ menor do que a CCAM e, após a moagem na betoneira, diminuição de apenas $7 \%$. $\mathrm{O}$ diâmetro médio da CCAN foi praticamente o dobro da CCAM, o que mostra a menor cominuição da moagem na betoneira, resultado da menor energia aplicada aos grãos. Esses dados revelam que a automoagem da CCAN promoveu fragmentação dos grãos, entretanto não reproduziu os valores obtidos para a CCA moída.

A Figura 3 apresenta os resultados do ensaio de atividade pozolânica com cimento segundo a NBR 5753 (ABNT, 1992). O índice de atividade pozolânica (IAP) representa o inverso da distância (d) que separa os pontos do gráfico com a origem das coordenadas, multiplicado por 100 (ISAIA, 1995). Quanto maior o IAP, mais elevada é a atividade pozolânica, isto é, maior consumo de $\mathrm{CH}$ e menor alcalinidade total.

A Figura 4 apresenta o difratograma de raios $\mathrm{X}$ (DRX) da cinza moída, evidenciando-se vários picos de cristobalita, o que confere caráter cristalino a essa amostra, em razão de sua obtenção em temperaturas mais altas (acima de $600^{\circ} \mathrm{C}$ ) e da presença de teor de potássio relativamente alto.

\begin{tabular}{|c|c|c|c|c|c|}
\hline Propriedades & Cimento & CCAM $^{1}$ & $\mathrm{CCAN}^{2}$ & CCAN15 $^{3}$ & CCAN25 ${ }^{3}$ \\
\hline $\begin{array}{l}\frac{\text { Físicas }}{\text { Massa específica, } \mathrm{kg} / \mathrm{dm}^{3}} \\
\text { Área específica } \mathrm{BET}, \mathrm{m}^{2} / \mathrm{g} \\
\text { Resíduo } \# 0,075 \mathrm{~mm}, \% \\
\text { Início de pega, min } \\
\text { Fim de pega, min }\end{array}$ & $\begin{array}{r}3,06 \\
1,44 \\
2,98 \\
157,00 \\
205,00\end{array}$ & $\begin{array}{r}2,09 \\
19,67 \\
82,18\end{array}$ & $\begin{array}{r}1,41 \\
49,25 \\
4,97\end{array}$ & $\begin{array}{r}1,96 \\
44,41 \\
9,09\end{array}$ & $\begin{array}{r}1,93 \\
45,01 \\
4,84\end{array}$ \\
\hline $\begin{array}{l}\text { Resistência à compressão } \\
1 \text { dia, } \mathrm{MPa} \\
3 \text { dias, } \mathrm{MPa} \\
7 \text { dias, } \mathrm{MPa} \\
28 \text { dias, } \mathrm{MPa}\end{array}$ & $\begin{array}{l}15,00 \\
26,30 \\
32,20 \\
40,00\end{array}$ & & & & \\
\hline $\begin{array}{l}\text { Análise granulométrica } \\
\text { Diâmetro médio, } \mu \mathrm{m} \\
\text { Diâmetro }<10 \%, \mu \mathrm{m} \\
\text { Diâmetro }<90 \%, \mu \mathrm{m}\end{array}$ & $\begin{array}{r}11,50 \\
1,30 \\
41,60\end{array}$ & $\begin{array}{r}15,50 \\
2,40 \\
54,10\end{array}$ & $\begin{array}{l}\text { n.d. } \\
\text { n.d. } \\
\text { n.d. }\end{array}$ & $\begin{array}{r}33,20 \\
5,20 \\
80,50\end{array}$ & $\begin{array}{r}26,70 \\
4,30 \\
69,40\end{array}$ \\
\hline $\begin{array}{l}\text { Análise química, \% } \\
\mathrm{Perda} \text { ao fogo } \\
\mathrm{SiO}_{2} \\
\mathrm{Al}_{2} \mathrm{O}_{3} \\
\mathrm{Fe}_{2} \mathrm{O}_{3} \\
\mathrm{CaO} \\
\mathrm{MgO} \\
\mathrm{SO}_{3} \\
\mathrm{Na}_{2} \mathrm{O} \\
\mathrm{K}_{2} \mathrm{O}\end{array}$ & $\begin{array}{r}1,31 \\
18,92 \\
4,32 \\
2,58 \\
60,15 \\
4,91 \\
3,19 \\
- \\
-\end{array}$ & $\begin{array}{r}0,25 \\
94,84 \\
0,39 \\
0,54 \\
1,32 \\
0,40 \\
0,01 \\
0,11 \\
1,45\end{array}$ & $\begin{array}{r}0,51 \\
95,04 \\
0,00 \\
0,44 \\
1,25 \\
0,45 \\
0,01 \\
0,09 \\
1,40\end{array}$ & & \\
\hline
\end{tabular}

${ }^{1}$ CCAM: CCA moída por $1 \mathrm{~h}$ em moinho de bolas; ${ }^{2}$ CCAN: CCA natural, conforme amostrada; ${ }^{3}$ CCAN15 e CCAN25: CCA natural nos teores de $15 \%$ e $25 \%$ respectivamente, moídas na betoneira juntamente com os demais materiais a seco.

Tabela 1 - Características físicas, mecânicas e químicas dos materiais cimentícios 


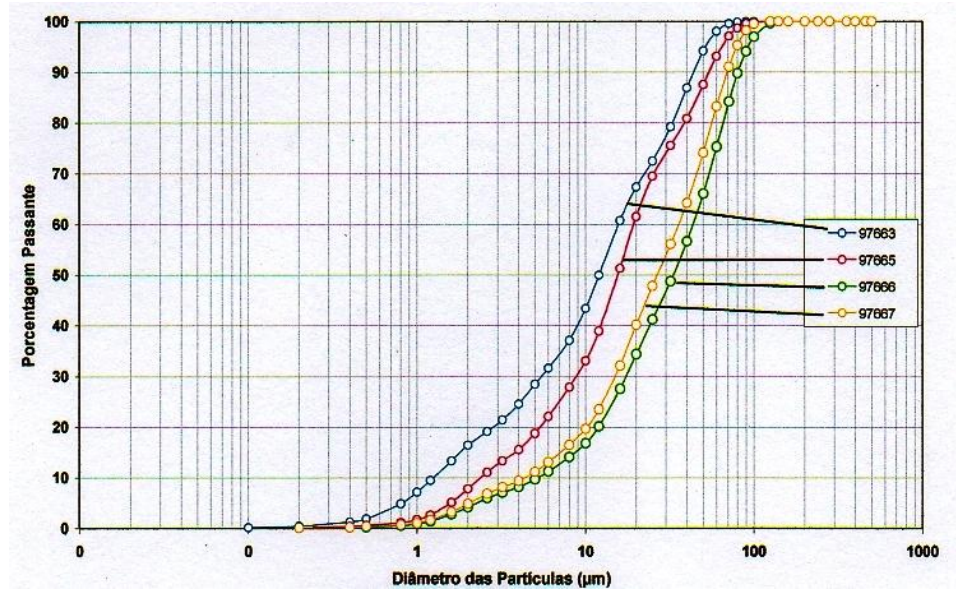

Legenda:

97663: Cimento Portland CPIIF;

97665: CCA moída por $1 \mathrm{~h}$;

97666: CCAN15;

97667: CCAN25.

Figura 2 - Curvas granulométricas dos materiais cimentícios por granulometria a laser

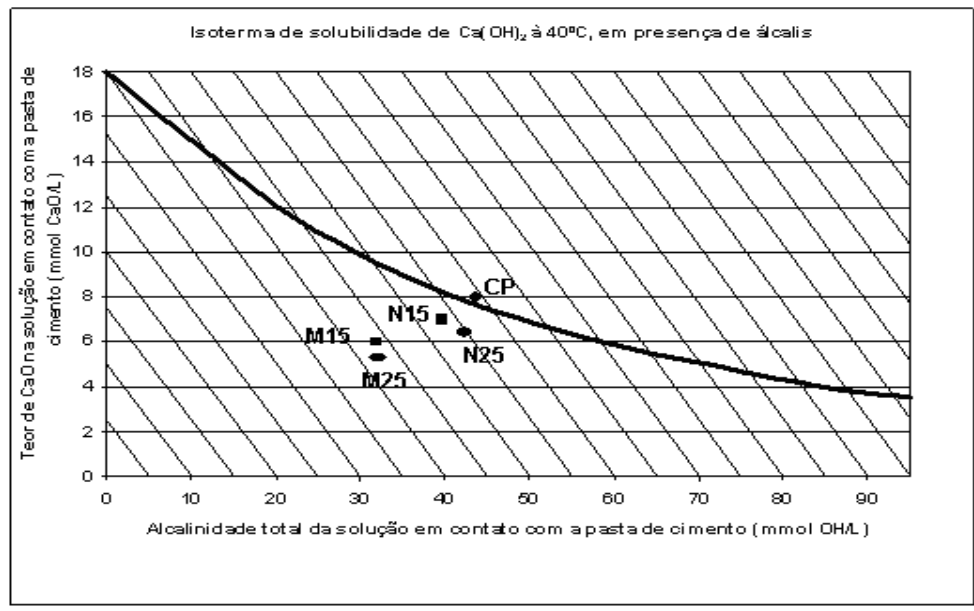

Legenda:

$\mathrm{CP}=$ cimento Portland;

M15: CCAM Com $15 \%$ de CCA;

M25: CCAM com $25 \%$ de CCA

N15: CCAN com $15 \%$ de CCA

N25: CCAN com $25 \%$ de CCA.

Figura 3 - Atividade pozolânica com cimento segundo a NBR 5733

CCA

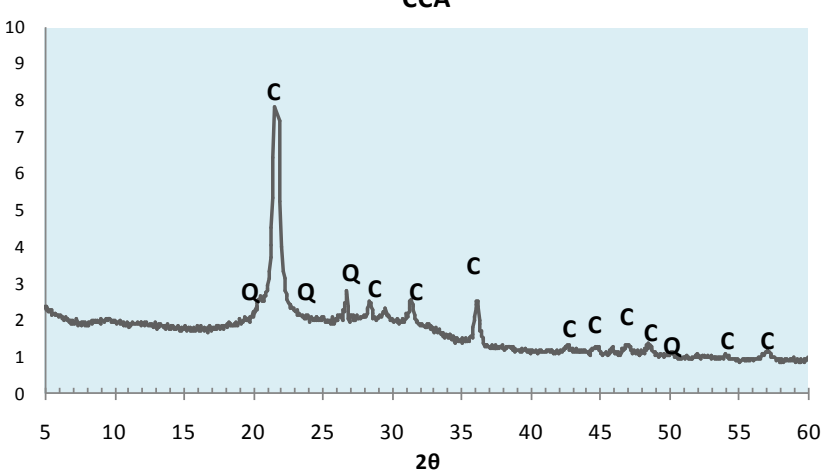

Legenda:

$\mathrm{C}=$ cristobalita;

$\mathrm{C}=$ quartzo.

Figura 4 - Difratograma de raios $\mathrm{X}$ de amostra de cinza de casca de arroz moída 
Os ensaios termogravimétricos foram realizados com gás nitrogênio 5.0 analítico para proceder à proteção da balança (fluxo de $20 \mathrm{ml} / \mathrm{min}$ ) e a purga dos gases volatilizados (fluxo de $60 \mathrm{ml} / \mathrm{min}$ ). A taxa de aquecimento foi $10{ }^{\circ} \mathrm{C} / \mathrm{min}$, de $30{ }^{\circ} \mathrm{C}$ até $1.000{ }^{\circ} \mathrm{C}$, em cadinho de alumina. A massa das amostras foi de $40 \mathrm{mg}$, para padronizar o ensaio e evitar distorções decorrentes da diferente quantidade de massa, o que poderia repercutir na difusão dos voláteis através da estrutura da amostra.

As Figuras 5 e 6 apresentam as análises térmica diferencial (DTA) e termogravimétrica (TG) da CCAN e da CCAM, ambas apresentando perda de massa $<2 \%$ até $200{ }^{\circ} \mathrm{C}$, devido à água adsorvida. Para a CCAN, a partir dessa temperatura, não se observam picos endotérmicos relevantes, a não ser perda de massa devido a materiais voláteis, perda de água de constituição e combustão do carbono. Para a CCAM, observa-se pico a $343{ }^{\circ} \mathrm{C}$, pela perda de água de constituição, em vista da maior finura dos grãos, o que facilita a remoção dos voláteis e dos materiais carbonosos.

\section{Características físicas dos agregados}

Foram utilizadas duas areias naturais quartzosas, fina e grossa, enquadradas na zona utilizável da NBR 7211 (ABNT, 2005), provenientes de Santa Maria, RS, secas em estufa, peneiradas na \#4,8 $\mathrm{mm}$ e estocadas em cubas de alvenaria. Foram empregadas britas diabásicas, provenientes de Itaára, RS, classificadas como 1 e 2 de acordo com a NBR 7211, lavadas e peneiradas entre \#19 mm e \#6,3 $\mathrm{mm}$, secas ao ar e estocadas também em cubas. Realizou-se composição granulométrica a partir de várias proporções entre os dois agregados, pelo ensaio da massa unitária compactada a seco. Os valores máximos dessas massas apontaram a proporção de $50 \%$ para cada uma, o que representou o menor índice de vazios. A Tabela 2 mostra os resultados das características físicas dos agregados.

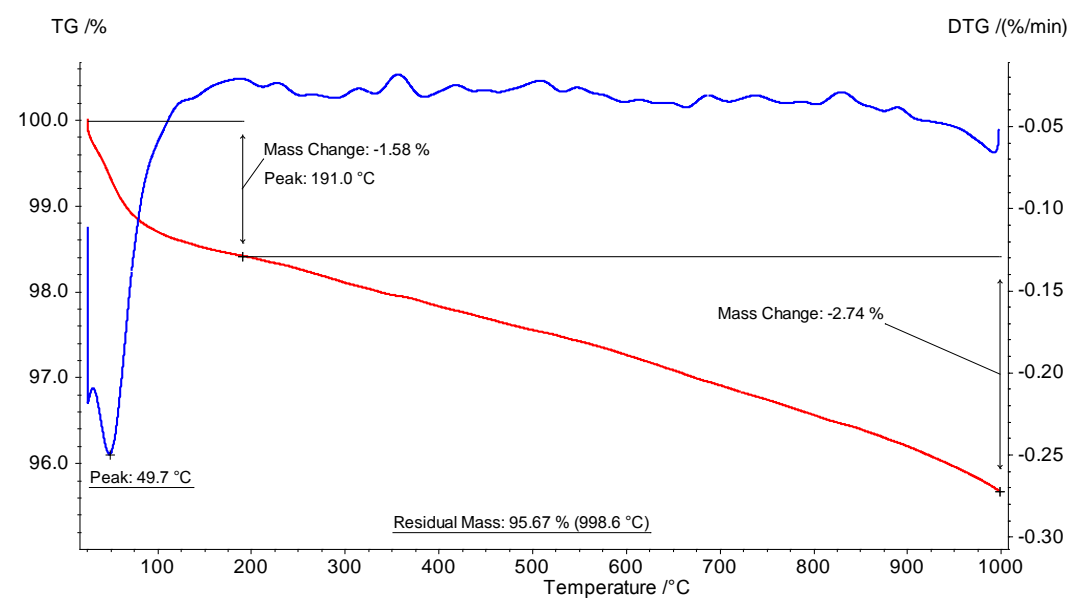

Figura 5 - DTA e TG da CCAN

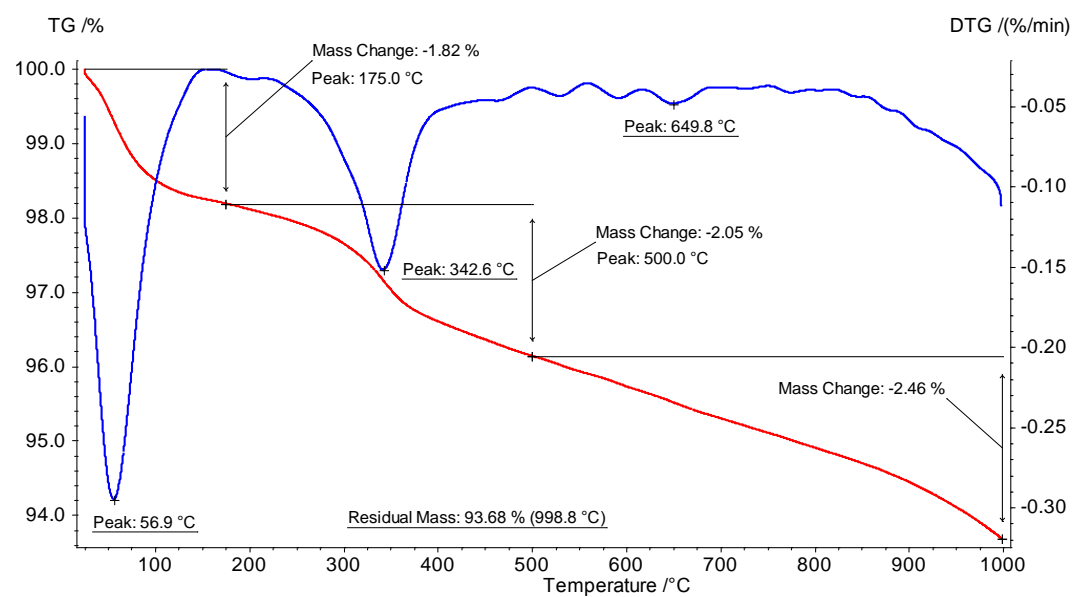

Figura 6 - DTA e TG da CCAM 


\begin{tabular}{|c|c|c|c|c|c|c|}
\hline & \multicolumn{3}{|c|}{ Agregados miúdos } & \multicolumn{3}{|c|}{ Agregados graúdos } \\
\hline & Areia 1 & Areia 2 & Areia 1+2 & Brita 1 & Brita 2 & Brita 1+2 \\
\hline Massa específica, $\mathrm{kg} / \mathrm{dm}^{3}$ & 2,60 & 2,63 & 2,62 & 2,55 & 2,49 & 2,52 \\
\hline Massa unitária solta, $\mathrm{kg} / \mathrm{dm}^{3}$ & 1,51 & 1,57 & 1,54 & 1,40 & 1,39 & 1,40 \\
\hline Módulo de finura & 2,81 & 1,89 & 2,35 & 5,42 & 6,91 & 6,17 \\
\hline D. máx. característica, mm & 4,75 & 1,18 & 4,75 & 9,5 & 19 & 19 \\
\hline
\end{tabular}

Tabela 2 - Características físicas dos agregados

\begin{tabular}{|c|c|c|c|c|c|c|}
\hline Traços & CCA \% & Relação a/mc & Cimento kg/m & CCA kg/m $\mathrm{m}^{3}$ & Areia kg/m ${ }^{3}$ & Aditivo $\mathrm{dm}^{3} / \mathrm{m}^{3}$ \\
\hline \multirow{3}{*}{ REF } & & 0,45 & 407 & & 688 & 0,1 \\
\hline & & 0,55 & 320 & & 779 & 0,3 \\
\hline & & 0,65 & 263 & & 838 & 0,1 \\
\hline \multirow{3}{*}{ M15 } & \multirow{3}{*}{15} & 0,45 & 346 & 61,1 & 664 & 1,3 \\
\hline & & 0,55 & 272 & 47,9 & 760 & 1,4 \\
\hline & & 0,65 & 223 & 39,4 & 822 & 1,2 \\
\hline \multirow{3}{*}{ M25 } & \multirow{3}{*}{25} & 0,45 & 305 & 102 & 647 & 1,8 \\
\hline & & 0,55 & 240 & 79,8 & 747 & 1,8 \\
\hline & & 0,65 & 197 & 65,7 & 812 & 1,3 \\
\hline \multirow{3}{*}{ N15 } & \multirow{3}{*}{15} & 0,45 & 346 & 61,1 & 627 & 2,2 \\
\hline & & 0,55 & 272 & 47,9 & 732 & 2,1 \\
\hline & & 0,65 & 223 & 39,4 & 799 & 2,2 \\
\hline \multirow{3}{*}{$\mathrm{N} 25$} & \multirow{3}{*}{25} & 0,45 & 305 & 102 & 586 & 3,6 \\
\hline & & 0,55 & 240 & 79,8 & 699 & 3,2 \\
\hline & & 0,65 & 197 & 65,7 & 772 & 3,1 \\
\hline
\end{tabular}

Pedra: $1.095(0,45), 1.099(0,55), 1.101(0,65) \mathrm{kg} / \mathrm{m}^{3}$

Água: $183(0,45), 176(0,55), 171(0,65) \mathrm{dm}^{3}$

Tabela 3 - Consumo de materiais por metro cúbico de concreto

\section{Aditivo}

O abatimento $80 \mathrm{~mm} \pm 20 \mathrm{~mm}$ foi obtido por aditivo superplastificante à base de carboxilatos, com densidade $1,1 \mathrm{~kg} / \mathrm{dm}^{3}$ e $30 \%$ de sólidos. Sua fase líquida foi descontada da água adicionada ao concreto.

\section{Concreto}

Foram dosadas cinco famílias de misturas: referência (REF), com $100 \%$ de cimento; CCAM15 (M15), com 15\% de substituição de cimento, em massa, por CCAM; CCAM25 (M25): idem, com 25\% de substituição; CCAN15 (N15): com $15 \%$ de substituição de cimento, em massa, por CCAN; e CCAN25 (N25): idem, com 25\% de substituição. Em cada família foram moldados traços com três relações água/materiais cimentícios $(\mathrm{a} / \mathrm{mc}): 0,45,0,55$ e 0,65 . Para compensar o aumento do teor de pasta nos traços com CCAN ou CCAM, devido a sua menor massa específica, manteve-se constante o volume de argamassa $\left(\mathrm{V}_{\text {arg }}\right)$ seca em 50\%, diminuindo-se na areia o aumento do volume de pasta. A Tabela 3 apresenta a quantidade de materiais por metro cúbico.

A sequência de colocação e o tempo de mistura dos materiais na betoneira foram citados no estudo prévio com CCA natural e moída em 2.1. Após a mistura foram medidos abatimento, temperatura do concreto e do ar, massa específica e teor de ar incorporado. As moldagens dos CPs atenderam às normas específicas dos ensaios nomeados a seguir e o adensamento realizado em mesa vibratória. Permaneceram à temperatura ambiente de laboratório por $24 \mathrm{~h}$ recobertos com tecidos saturados, posteriormente desmoldados e acondicionados em câmara úmida a $23 \pm 2{ }^{\circ} \mathrm{C}$ e umidade relativa $>95 \%$, onde permaneceram até as datas dos ensaios. A massa específica média do concreto fresco foi de $2,3 \mathrm{~kg} / \mathrm{dm}^{3}$.

A moldagem dos CPs foi realizada conforme a NBR 5738 (ABNT, 2003a), e os ensaios foram realizados a 28 e 91 dias, conforme a NBR 5739 (ABNT, 2003b).

A resistência à tração por compressão diametral em CPs de $10 \mathrm{~cm}$ x $20 \mathrm{~cm}$ foi determinada conforme a NBR 7222 (ABNT, 1994), para 28 e 91 dias.

Os ensaios de retração foram realizados conforme a norma C490 (ASTM, 1996), moldando-se CPs prismáticos de $10 \mathrm{~cm}$ x $10 \mathrm{~cm}$ x $28,5 \mathrm{~cm}$, medindo-se as retrações a 1 (leitura inicial) 7, 28, 91, 182 e 300 dias. A temperatura e umidade relativa do ambiente estiveram dentro dos intervalos preconizados na norma mencionada. 


\section{Análise e discussão dos resultados}

\section{Resistência à compressão axial}

As Figuras 6 e 7 apresentam os resultados dos ensaios de resistência à compressão axial, a $28 \mathrm{e}$ 91 dias.

Os traços CCAM apresentaram as resistências mais elevadas, principalmente M15 para ambas as idades, mostrando que a moagem prévia da cinza foi determinante para o aumento da resistência à compressão devido à menor dimensão das partículas, o que favoreceu a nucleação de compostos hidratados. Os traços CCAN apresentaram menores resistências a 28 dias que REF e menores ainda quando comparados aos CCAM, porque as partículas de CCAN apresentaram grãos maiores, e o efeito das reações pozolânicas não foi muito significativo nessa idade. Os traços N25 apresentaram as menores resistências pelo maior tamanho e teor de partículas mais grossas.

A 91 dias, a progressão das reações pozolânicas possibilitou ao traço N15 crescimento de resistência, em patamar similar aos traços CCAM, superando em até $18 \%$ a resistência de REF. A partir de a/mc $=0,55$, a inflexão da curva de N15 foi mais pronunciada quando comparada aos demais traços, mostrando que, para menores $\mathrm{a} / \mathrm{mc}$, maior foi o efeito positivo da CCAN, que praticamente se igualou em resistência aos traços CCAM para a relação $\mathrm{a} / \mathrm{mc}=0,45$. O aumento de 28 para 91 dias foi benéfico para N15, com resultados iguais ou maiores que os $\mathrm{REF}_{91}$, igualando-se, praticamente, com os M25.

A maior finura e reatividade de CCAM contribuiu para o aumento da resistência, mais para M15 do que para M25. As misturas N15 apresentaram aumento de resistência em relação às $\mathrm{REF}_{91}$ enquanto para N25 a resistência diminuiu para percentuais similares, quando comparadas aos dos traços M25. O teor de $15 \%$ foi mais compensador do que $25 \%$, especialmente para os traços CCAN. A menor finura da CCAN afetou negativamente para os traços com maior teor e a/mc mais alta, quando comparadas às resistências dos traços REF.

\section{Viabilidade técnica}

A Tabela 4 apresenta as relações a/mc, consumo de cimento para três níveis de resistências de dosagem a 28 dias, 25, 30 e $40 \mathrm{MPa}$, que são usualmente empregadas no cálculo de estruturas.

Os traços $\mathrm{f}_{\mathrm{c} 28-25 \mathrm{MPa}}$ preenchem a condição $\mathrm{a} / \mathrm{mc} \leq$ 0,65 (classe de agressividade I: rural, NBR 12655); $\mathrm{f}_{\mathrm{c} 28-30 \mathrm{MPa}}$, a condição $\mathrm{a} / \mathrm{mc} \leq 0,60$ (classe II: urbana); e $\mathrm{f}_{\mathrm{c} 28-40 \mathrm{MPa}}$, a condição $\mathrm{a} / \mathrm{mc} \leq 0,55$ (classe III: marinha). Os consumos mínimos de materiais cimentícios da NBR 12655 (ABNT, 1992) foram cumpridos.

$\mathrm{O}$ traço N25 preencheu somente as condições de $\mathrm{f}_{\mathrm{c} 28-25 \mathrm{MPa}}$, com consumo de cimento $63 \%$ mais elevado que REF, não sendo economicamente viável. Os demais apresentaram consumos abaixo da referência: N15: -12\% (25 MPa), -9\% (30 MPa) e $-6 \%$ (40 MPa). Os traços CCAM apresentaram consumos menores para as mesmas resistências do que com CCAN, pelas razões apontadas em 3.1. Houve crescimento superior a $30 \%$ de $\mathrm{f}_{\mathrm{c} 2828}$ para $\mathrm{f}_{\mathrm{c} 91}$ dos traços $\mathrm{N} 15$, alcançando $39,3 \mathrm{MPa}\left(\mathrm{f}_{\mathrm{c} 28-}\right.$ 30MPa $)$ e $55,1 \mathrm{MPa}\left(\mathrm{f}_{\mathrm{c} 28-40 \mathrm{MPa}}\right)$, que os elevaria para esses níveis de resistências de dosagem mais altas se fossem ensaiados para $\mathrm{f}_{\mathrm{c} 91}$.

As resistências à compressão axial da Tabela 4 a 91 dias são utilizadas nos cálculos das regressões a seguir.

\begin{tabular}{c|l|r|r|r|r|r}
\hline $\begin{array}{c}\mathbf{f}_{\mathbf{c} 28} \\
\mathbf{M P a}\end{array}$ & \multicolumn{1}{|c|}{$\begin{array}{c}\text { Parâmetros de } \\
\text { análise }\end{array}$} & REF & $\begin{array}{r}\text { CCA } \\
\text { M15 }\end{array}$ & $\begin{array}{r}\text { CCA } \\
\text { M25 }\end{array}$ & $\begin{array}{r}\text { CCA } \\
\text { N15 }\end{array}$ & $\begin{array}{c}\text { CCA } \\
\text { N25 }\end{array}$ \\
\hline \multirow{2}{*}{$\mathbf{2 5}$} & Relação a/mc & 0,63 & 0,65 & 0,61 & 0,61 & 0,42 \\
& Consumo cimento & 271,00 & 223,00 & 212,00 & 241,00 & 332,00 \\
& $\mathrm{f}_{\mathrm{c} 91}\left(\mathrm{p} / \mathrm{f}_{\mathrm{c} 28}=25 \mathrm{MPa}\right)$ & 28,90 & 33,10 & 32,20 & 32,10 & 32,70 \\
\hline \multirow{2}{*}{$\mathbf{3 0}$} & Relação a/mc & 0,56 & 0,60 & 0,55 & 0,53 & \\
& Consumo cimento & 313,00 & 247,00 & 239,00 & 284,00 & \\
& $\mathrm{f}_{\mathrm{c} 91}\left(\mathrm{p} / \mathrm{f}_{\mathrm{c} 28}=30 \mathrm{MPa}\right)$ & 33,20 & 36,80 & 37,50 & 39,30 & \\
\multirow{2}{*}{$\mathbf{4 0}$} & Relação a/mc & 0,46 & 0,48 & 0,47 & 0,42 & \\
& Consumo cimento & 392,00 & 322,00 & 289,00 & 369,00 & \\
& $\mathrm{f}_{\mathrm{c} 91}\left(\mathrm{p} / \mathrm{f}_{\mathrm{c} 28}=40 \mathrm{MPa}\right)$ & 41,80 & 48,60 & 47,40 & 55,10 & \\
\hline
\end{tabular}

${ }^{1}$ Adotou-se o valor mínimo da NBR 12655 para a classe I: a/mc $\leq 0,65$

Tabela 4 - Relações a/mc e consumo de cimento para concretos com $\mathrm{f}_{\mathrm{c} 28} 25,30$ e $40 \mathrm{MPa}$ 


\section{Resistência à tração por compressão diametral}

As Figuras $8 \mathrm{a}$ e $8 \mathrm{~b}$ mostram os resultados de $\mathrm{f}_{\mathrm{t}}$ comparados com as resistências $\mathrm{f}_{\mathrm{c} 28}$ e $\mathrm{f}_{\mathrm{c} 91}$, por regressão simples, com coeficientes $\mathrm{r}^{2}$ muito fortes $\left(r^{2} \geq 0,90\right)$.

$\mathrm{O}$ traço M15 apresentou resistências $\mathrm{f}_{\mathrm{t} 28} \geq \mathrm{REF}$, enquanto M25 incrementou para $\mathrm{f}_{\mathrm{c}} \leq 40 \mathrm{MPa}$. O traço N15 apresentou desempenho inferior ao REF em todas as faixas de estudo, em ambas as idades; o N25, apesar da queda acentuada em $\mathrm{f}_{\mathrm{c}}$, mostrou valores de $f_{t}$ superiores em relação ao teor $15 \%$, em igualdade de $\mathrm{f}_{\mathrm{c}}$.

A Figura 8 mostra os valores da equação da NBR 6118 (ABNT, 2007):

$\mathrm{f}_{\mathrm{t}}=0,3 \cdot \mathrm{f}_{\mathrm{c}}{ }^{2 / 3}$

A maioria dos traços apresentou valores superiores aos da norma a 28 dias - exceção dos N15 e M25 para $\mathrm{f}_{\mathrm{c}} \geq 40 \mathrm{MPa}$. O aumento de CCA natural e moída, de $15 \%$ para $25 \%$, foi mais benéfico para $\mathrm{f}_{\mathrm{c}}$ $\leq 30 \mathrm{MPa}$, sugerindo que os efeitos físicos e pozolânicos são mais efetivos quando a porosidade da matriz cimentícia é maior (menores relações $\mathrm{a} / \mathrm{mc})$.

A Figura 8 mostra os valores médios da equação proposta por Ahmad e Shah (1985):

$\mathrm{f}_{\mathrm{t}}=0,305 \cdot \mathrm{f}_{\mathrm{c}}^{0,55}$

Os valores desse modelo são nitidamente inferiores aos da NBR 6118 e aos demais desta pesquisa. Ahmad e Shah (1985) enfatizam que a resistência à tração do concreto depende muito do tipo de agregado e das condições de cura inicial, cuja influência em $f_{t}$ é mais importante do que no comportamento de $\mathrm{f}_{\mathrm{c}}$.

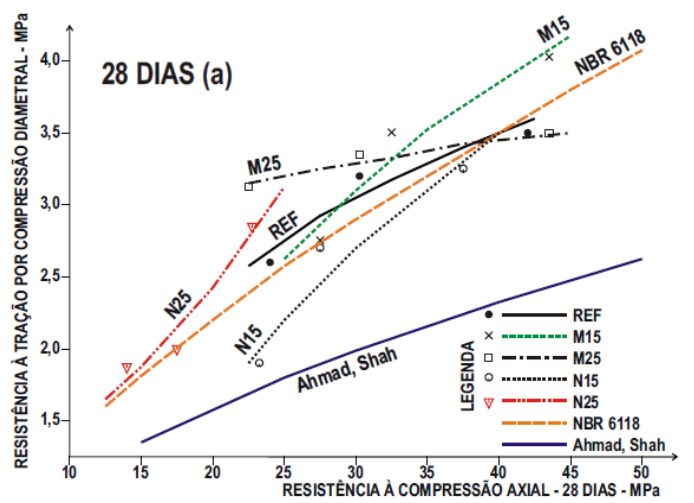

(a) 28 dias
Na Figura 8b, para 91 dias, observa-se crescimento de $f_{t}$ para todos os traços, especialmente REF, com valores superiores a todos os traços com CCA, exceção da relação a/mc $=0,45$ de M15. Pela NBR 6118 , o traço N15 continua apresentando valores inferiores para todas as relações a/mc, enquanto os demais são próximos ou superiores.

A Tabela 5 mostra as resistências $\mathrm{f}_{\mathrm{t}}$ para as classes nomeadas. O traço N15 apresenta queda mais significativa, $21 \%$ em relação ao $\mathrm{REF}_{28}$, para $\mathrm{f}_{\mathrm{c} 28-}$ $25 \mathrm{MPa}$, entretanto, a 91 dias, o valor sobe para o patamar próximo ao do traço $\mathrm{M} 15$, para $\mathrm{f}_{\mathrm{c}} \geq 40$ $\mathrm{MPa}$. Os ganhos são maiores na relação entre $91 \mathrm{e}$ 28 dias para as resistências mais baixas, pela disponibilidade de mais espaço para formação de compostos por via química, assim como tamponamento por via física.

A CCAM apresentou bom desempenho em relação ao REF em todos os níveis de resistência, enquanto a N15, somente acima de $30 \mathrm{MPa}$. Já para N25, em vista de sua baixa resistência $f_{c}$, somente poderia ser utilizada para $25 \mathrm{MPa}$. Pela NBR 6118, todos os traços com CCAM mostram desempenho adequado, enquanto a CCAN somente alcança o patamar dessa norma a 91 dias. Esses resultados mostram que a cinza natural, por sua menor finura e grãos de maiores dimensões, enfraquece a zona de transição em idade mais baixa (28 dias), influenciando mais a resistência à tração do que à compressão.

As relações $\left(\mathrm{f}_{\mathrm{t}} / \mathrm{f}_{\mathrm{c}}\right)$ a 28 dias da Tabela 5 permaneceram no intervalo 0,09 e 0,13 , dentro da variação 0,08 a 0,14 citada por Mindess, Young e Darwin (2003).

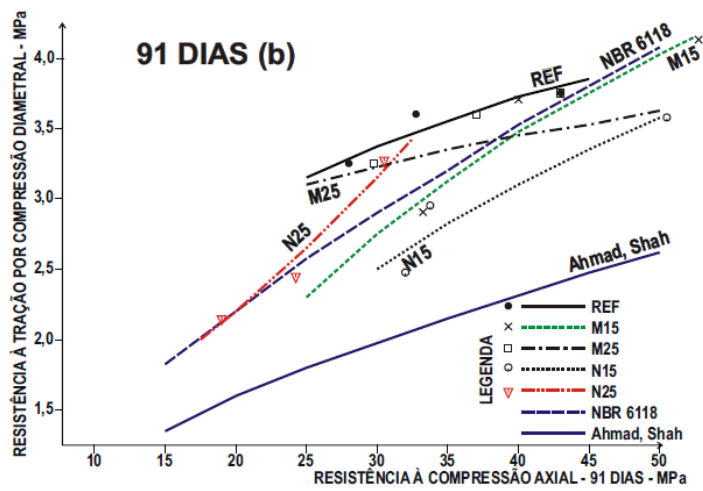

(b) 91 dias

Figura 7 - Resistência à compressão diametral x compressão axial a 28 dias (a) e a 91 dias (b) 


\begin{tabular}{|c|c|c|c|c|c|c|c|}
\hline $\begin{array}{c}\mathbf{f}_{\mathrm{c} 28} \\
\mathbf{M P a} \\
\end{array}$ & & REF & M15 & M25 & N15 & N25 & $\begin{array}{l}\text { NBR } \\
6118 \\
\end{array}$ \\
\hline \multirow{3}{*}{$\begin{array}{c}25 \\
\text { (C15) }\end{array}$} & $\mathrm{f}_{\mathrm{t} 28}, \mathrm{MPa}$ & \multirow{3}{*}{$\begin{array}{l}2,72 \\
1,00\end{array}$} & 2,60 & 3,18 & 2,16 & 3,19 & 2,57 \\
\hline & $\mathrm{f}_{128} / \mathrm{f}_{\mathrm{c} 28}$ & & 0,10 & 0,13 & 0,09 & 0,13 & 0,10 \\
\hline & $\mathrm{f}_{\mathrm{t} 28 \mathrm{CCA}} / \mathrm{f}_{\mathrm{t} 28 \mathrm{R}}$ & & 0,96 & 1,17 & 0,79 & 1,17 & 0,94 \\
\hline \multirow{3}{*}{$\begin{array}{c}30 \\
(\mathbf{C} 20)\end{array}$} & $\mathrm{f}_{128}, \mathrm{MPa}$ & 3,03 & 3,10 & 3,29 & 2,70 & & 2,90 \\
\hline & $\mathrm{f}_{\mathrm{t} 22} / \mathrm{f}_{\mathrm{c} 28}$ & 0,10 & 0,10 & 0,11 & 0,09 & & 0,10 \\
\hline & $\mathrm{f}_{\mathrm{t} 28 \mathrm{CCA}} / \mathrm{f}_{\mathrm{t} 28 \mathrm{R}}$ & 1,00 & 1,02 & 1,09 & 0,89 & & 0,96 \\
\hline \multirow{3}{*}{$\begin{array}{c}40 \\
(\mathbf{C 3 0})\end{array}$} & $\mathrm{f}_{\mathrm{t} 28}, \mathrm{MPa}$ & 3,53 & 3,8 & 3,46 & 3,56 & & 3,51 \\
\hline & $\mathrm{f}_{\mathrm{t} 28} / \mathrm{f}$ & 0,0 & 0,10 & 0,09 & 0,0 & & 0,09 \\
\hline & $\mathrm{f}_{\mathrm{t} 28 \mathrm{CCA} /} / \mathrm{f}_{\mathrm{t} 28 \mathrm{R}}$ & 1,00 & 1,10 & 0,98 & 1,01 & & 0,99 \\
\hline
\end{tabular}

Tabela 5 - Resistências à compressão diametral para concretos com $\mathrm{f}_{\mathrm{c} 28} \mathrm{DE} 25,30$ e $40 \mathrm{MPa}$

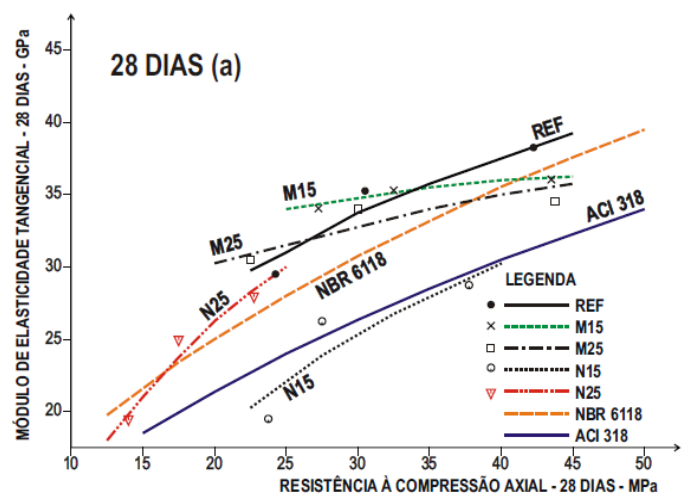

(a) 28 dias

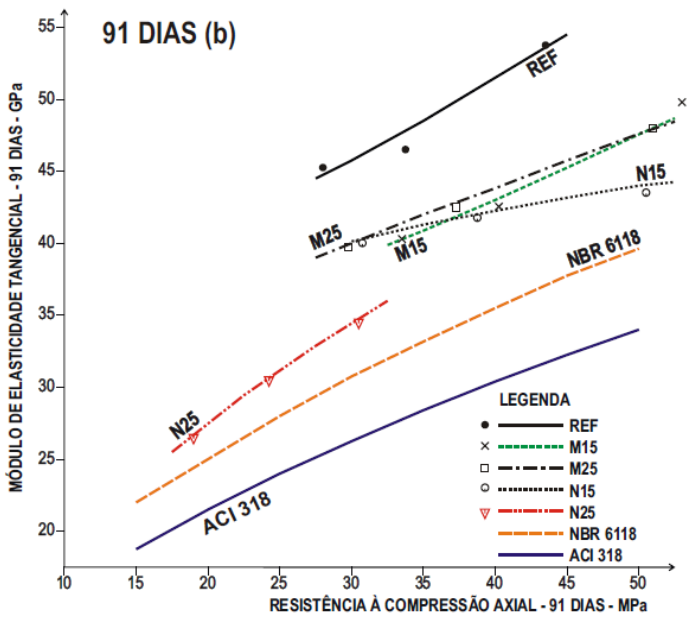

(b) 91 dias

Figura 8 - Módulo de elasticidade x resistência à compressão a 28 dias (a) e 91 dias (b)

\section{Módulo de elasticidade}

Os ensaios do módulo de elasticidade foram realizados conforme a NBR 8522 (ABNT, 2003), plano de carga II (módulo tangente na origem), em CPs de $10 \mathrm{~cm}$ x $20 \mathrm{~cm}$. As Figuras $9 \mathrm{a}$ e $9 \mathrm{~b}$ mostram os resultados comparados com as resistências $f_{c}$ a 28 e 91 dias, por regressão simples, com coeficientes $r^{2}$ fortes ou muito fortes $\left(r^{2} \geq 0,80\right)$.

Pela Figura 8a, a 28 dias, todos os traços com exceção do $\mathrm{N} 15$, apresentam $\mathrm{E}_{\mathrm{c}}$ coerentes entre si e com os propostos pela NBR 6118 (ABNT, 2007) pela equação:

$\mathrm{E}_{\mathrm{c}}=5600 . \mathrm{f}_{\mathrm{c}}^{1 / 2}$

É mostrada também a curva do ACI 318 (ACI, 2008) pela equação:

$\mathrm{E}_{\mathrm{c}}=4805 . \mathrm{f}_{\mathrm{c}}^{0,5}$

Esta equação é para módulo de elasticidade secante, entretanto, apesar de as normas fornecerem diferentes denominações a $E_{c}$, todas levam à determinação do módulo tangente inicial, porque, após alguns ciclos de carga-descarga, a reta que liga os pontos da curva tensão-deformação das duas tensões de cálculo $\left(\begin{array}{lll}\sigma_{\mathrm{c} 1} & \mathrm{e} & \sigma_{\mathrm{c} 2}\end{array}\right)$ é aproximadamente paralela à reta tangente à curva na origem (SHEHATA, 2005).

Os traços N15 apresentaram módulos inferiores aos demais a 28 dias, observando-se na Figura $8 b$ aumento significativo a 91 dias, com resultados similares às misturas CCAM. A 91 dias, todos os traços ficaram abaixo do REF e acima dos valores da NBR 6118. Esse comportamento decorre do aumento do volume de pasta motivado pela substituição do cimento em massa, porque a CCA tem massa específica $35 \%$ inferior, conforme a Tabela 1. A diminuição do volume de agregado explica a diminuição do $\mathrm{E}_{\mathrm{c}}$ nesses traços, especialmente os de menor relação a/mc. Os traços CCAN apresentaram queda adicional em razão da menor finura dos grãos e zona de transição mais fraca. 


\begin{tabular}{c|l|r|r|r|r|r|r|r}
\hline $\begin{array}{c}\mathbf{f}_{\mathbf{c} 28} \\
\mathbf{M P a}\end{array}$ & & $\mathbf{R E F}$ & $\mathbf{M 1 5}$ & $\mathbf{M 2 5}$ & $\mathbf{N 1 5}$ & $\mathbf{N 2 5}$ & $\begin{array}{c}\text { NBR } \\
\mathbf{6 1 1 8}\end{array}$ & $\begin{array}{c}\text { ACI } \\
\mathbf{3 1 8}\end{array}$ \\
\hline $\mathbf{2 5}$ & $\mathrm{E}_{\mathrm{c} 28}, \mathrm{GPa}$ & 31,00 & 33,90 & 31,70 & 22,20 & 29,80 & 28,00 & 24,00 \\
& $\mathrm{E}_{\mathrm{c} 28 \mathrm{CCAA}} / \mathrm{E}_{\mathrm{c} 28 R E F}$ & 1,00 & 1,09 & 1,02 & 0,72 & 0,96 & 0,90 & 0,77 \\
\hline \multirow{3}{30}{} & $\mathrm{E}_{\mathrm{c} 28}, \mathrm{GPa}$ & 33,60 & 34,70 & 32,90 & 25,40 & & 30,70 & 26,30 \\
& $\mathrm{E}_{\mathrm{c} 28 \mathrm{CAA} / \mathrm{E}_{\mathrm{c} 8 R E F}}$ & 1,00 & 1,03 & 0,98 & 0,76 & & 0,91 & 0,78 \\
\hline $\mathbf{4 0}$ & $\mathrm{E}_{\mathrm{c} 28, \mathrm{GPa}}$ & 37,60 & 35,90 & 34,80 & 28,10 & & 35,40 & 30,40 \\
& $\mathrm{E}_{\mathrm{c} 28 \mathrm{CAA}} / \mathrm{E}_{\mathrm{c} 28 \mathrm{REF}}$ & 1,00 & 0,95 & 0,93 & 0,75 & & 0,94 & 0,81 \\
\hline
\end{tabular}

Tabela 6 - Módulos de elasticidade tangencial para concretos com $\mathrm{f}_{\mathrm{c} 28}=25,30$ e $40 \mathrm{MPa}$

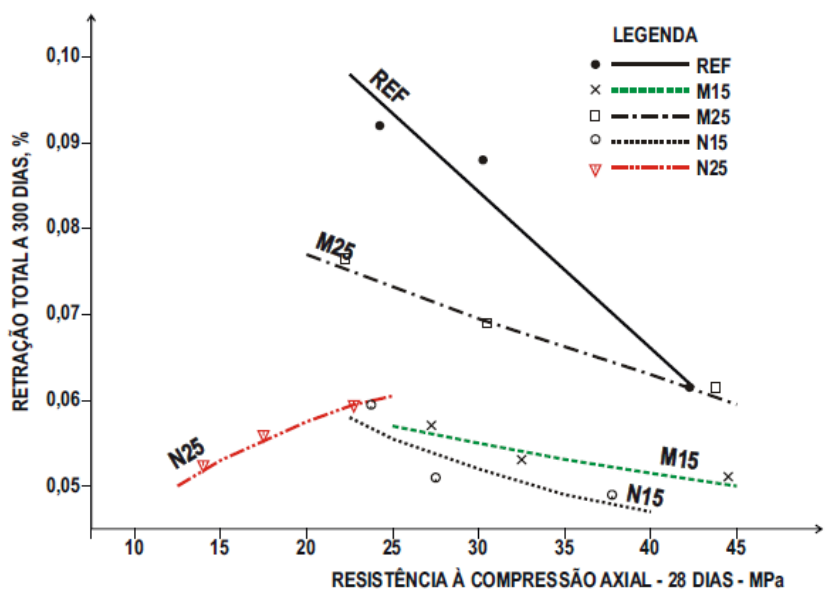

Figura 9 - Retração total a 300 dias x resistência à compressão a 28 dias

A Tabela 6 mostra que os $\mathrm{E}_{\mathrm{c}}$ dos traços CCAM são similares ao do REF. Somente o traço N15, a 28 dias, apresentou decréscimo do módulo, ao redor de $25 \%$, em relação ao concreto referência para $\mathrm{f}_{\mathrm{c} 28-25 \mathrm{MPa}}$, reproduzindo as tendências observadas nos ensaios de resistência à tração com compressão diametral (Resistência à tração por compressão diametral, item 3.3). Comparando-se os módulos obtidos pela NBR 6118 com os traços CCAM, observa-se que foram iguais ou superiores à previsão desta norma, a 28 dias. O traço N15 apresentou decréscimos entre $20 \%$ e $30 \%$ quando comparado com a NBR 6118 (ABNT, 2007), a 28 dias.

A 91 dias houve substancial recuperação para $\mathrm{N} 15_{25 \mathrm{MPa}}$, equiparando-se aos $\mathrm{E}_{\mathrm{c}}$ dos traços CCAM nessa mesma idade e nível de resistência. O traço N25 mostrou desempenho similar em relação às duas bases de comparação, para a resistência $\mathrm{f}_{\mathrm{c} 28}$ $25 \mathrm{MPa}$.

\section{Retração total}

A Figura 9 apresenta os resultados de retração total a 300 dias, comparados com $\mathrm{f}_{\mathrm{c} 28}$. Tomou-se a idade de 300 dias para a retração total, próximo das finais, com o intuito de compará-las com as resistências de dosagem. É um elemento de informação importante para projetistas a respeito das deformações intrínsecas totais (retração química, autógena e hidráulica), em ausência de carga e igualdade térmica, que a estrutura do concreto pode apresentar, em longo prazo, para calcular as armaduras adequadas e prevenir o desenvolvimento de possíveis fissuras por retração de origem interna.

A retração total diminuiu com o aumento da resistência porque, quando decresce a relação $\mathrm{a} / \mathrm{mc}$, reduz-se a água da pasta e há menos espaço disponível para a contração de volume devida aos esforços capilares. Os traços N25 apresentaram variação da retração contrária aos demais, não havendo explicação plausível para tal comportamento.

Os traços CCAM apresentaram retração abaixo do REF; M25 foi a que revelou valores mais elevados, provavelmente pelo maior refinamento dos poros ocasionado pelo incremento da reatividade, o que induziria a maior tensão capilar. As misturas M15 e N15 apresentaram variações volumétricas similares, abaixo de $0,060 \%$ em todas as relações $\mathrm{a} / \mathrm{mc}$, limite considerado adequado por diversos autores (ISAIA; GASTALDINI, 2007). 


\begin{tabular}{c|l|l|l|l|l|l}
\hline $\begin{array}{c}\mathbf{f}_{\mathbf{c 2 8}} \\
\mathbf{M P a}\end{array}$ & & $\mathbf{R E F}$ & $\mathbf{M 1 5}$ & $\mathbf{M 2 5}$ & $\mathbf{N 1 5}$ & $\mathbf{N 2 5}$ \\
\hline $\mathbf{2 5}$ & $\varepsilon_{\mathrm{c} 300,} \%$ & 0,093 & 0,057 & 0,074 & 0,056 & 0,061 \\
& $\varepsilon_{\mathrm{CAA}} / \varepsilon_{\text {ref }}$ & 1,000 & 0,610 & 0,800 & 0,600 & 0,660 \\
\hline $\mathbf{3 0}$ & $\varepsilon_{\mathrm{c} 300}, \%$ & 0,084 & 0,055 & 0,070 & 0,052 & \\
& $\varepsilon_{\mathrm{CAA}} / \varepsilon_{\text {ref }}$ & 1,000 & 0,650 & 0,830 & 0,620 & \\
\hline $\mathbf{4 0}$ & $\varepsilon_{\mathrm{c} 300}, \%$ & 0,066 & 0,052 & 0,063 & 0,047 & \\
& $\varepsilon_{\mathrm{CAA}} / \varepsilon_{\text {ref }}$ & 1,000 & 0,790 & 0,950 & 0,710 & \\
\hline
\end{tabular}

Tabela 7 - Retração total a 300 dias para concretos com $\mathrm{f}_{\mathrm{c} 28}$ de 25,30 e $40 \mathrm{MPa}$

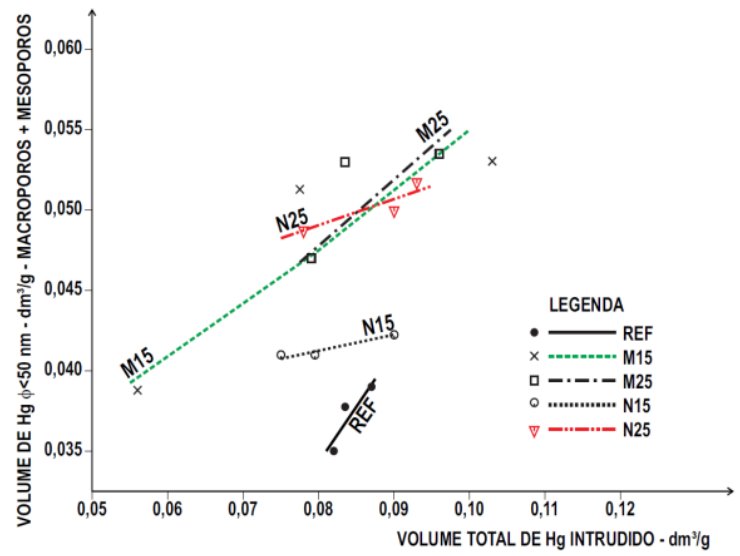

Figura 10 - Volume total de $\mathrm{Hg} \times$ Volume de $\mathrm{Hg}$ para $\varphi \leq 50 \mathrm{~nm}$ a 91 dias

Pela Tabela 7 a retração dos traços M15 e N15 foram similares, com tendência de valores menores para a CCAN e cerca de $40 \%$ inferiores ao REF. No traço M15, a retração variou de $39 \%$ a $21 \%$ abaixo do REF, para $\mathrm{f}_{\mathrm{c} 25}$ e $\mathrm{f}_{\mathrm{c} 40}$ respectivamente, enquanto as misturas M25 tiveram acréscimos entre $30 \%$ e $21 \%$ em relação à M15. Os menores valores da retração estão relacionados com as misturas N15 para os três níveis de resistência, provavelmente pela maior dimensão dos grãos da adição e a manutenção da estrutura porosa derivada da lignina e da celulose da casca.

\section{Microestrutura}

O estudo da microestrutura abrangeu ensaios de porosimetria por intrusão de mercúrio, água quimicamente combinada e MEV.

\section{Porosimetria por intrusão de mercúrio}

Utilizou-se porosímetro Micromeritics, Autopore II 9220, para determinação de poros até $3 \mathrm{~nm}$. A Figura 10 relaciona os $\mathrm{V}_{\text {Hg-total }}$ e os $\mathrm{V}_{\mathrm{Hg}}$ para $\varphi<50$ $\mathrm{nm}$ (microporos e mesoporos), a 91 dias.

$\mathrm{O}$ concreto REF apresentou pequena variação tanto no volume total (entre 0,080 e $0,090 \mathrm{dm}^{3} / \mathrm{g}$ ) quanto a $\varphi \leq 50 \mathrm{~nm}$ (entre 0,035 e $0,040 \mathrm{dm}^{3} / \mathrm{g}$ ), mostrando que os poros estão distribuídos em estreita faixa de dimensão. As retas dos traços M15 e M25 situaram-se acima do REF com distribuição mais ampla, entre 0,055 e $0,105 \mathrm{dm}^{3} / \mathrm{g}$ no $V_{\text {total }}$ e entre 0,040 e $0,055 \mathrm{dm}^{3} / \mathrm{g}$ no $V_{50 \mathrm{~nm}}$ indicando maior refinamento dos poros em todo o espectro de variação das resistências à compressão. O traço N15 situou-se acima do REF com reta em posição mais horizontal, mostrando discreto aumento dos poros inferiores a $50 \mathrm{~nm}$ e pequena variação desses volumes entre as relações a/mc extremas. A reta que posiciona os traços N25 está em situação similar às da CCAM, em posição mais horizontal e um pouco mais estendida do que N15, mostrando que o aumento do teor de CCA natural aumentou o refinamento dos poros.

Os cálculos por regressão na Tabela 8 foram realizados para $\mathrm{f}_{\mathrm{c} 91}$. $\mathrm{O} \mathrm{V}_{\text {Hgtotal }}$ foi similar ao REF, com exceção dos M15, para os níveis $f_{c 28-25 M P a} e$ $\mathrm{f}_{\mathrm{c} 28-40 \mathrm{MPa}}$, que foram significativamente mais alto e mais baixo respectivamente. Os traços com CCAN apresentaram volumes de $1 \%$ a $12 \%$ menores que REF e, com exceção dos M15 para $f_{\text {c28-40MPa, }}$ inferiores aos traços com CCAM.

Houve refinamento dos poros das misturas CCAM, com acréscimo entre $25 \%$ e $45 \%$ para $\varphi<50 \mathrm{~nm}$, e entre $10 \%$ e $25 \%$ nos traços CCAN, em relação ao concreto REF. 


\begin{tabular}{c|l|c|c|c|c|c}
\hline $\begin{array}{c}\mathbf{f}_{\text {c28 }} \\
\text { MPa }\end{array}$ & & REF & M15 & M25 & N15 & N25 \\
\hline \multirow{2}{*}{25} & Volume total Hg, ml/g & 0,086 & 0,103 & 0,091 & 0,085 & 0,076 \\
& V $_{\text {HgTotalCCA }} / \mathrm{V}_{\text {HgTotalREF }}$ & 1,000 & 1,120 & 1,060 & 0,990 & 0,880 \\
& Volume Hg $\varphi \leq 50 \mathrm{~nm}, \mathrm{ml} / \mathrm{g}$ & 0,038 & 0,055 & 0,053 & 0,042 & 0,048 \\
\hline \multirow{2}{*}{$\mathbf{3 0}$} & Volume total Hg, ml/g & 0,084 & 0,090 & 0,086 & 0,080 & \\
& V $_{\text {HgTotalCCA }} / \mathrm{V}_{\text {HgTotalREF }}$ & 1,000 & 1,070 & 1,020 & 0,950 & \\
& Volume Hg $\varphi \leq 50 \mathrm{~nm}, \mathrm{ml} / \mathrm{g}$ & 0,036 & 0,052 & 0,051 & 0,041 & \\
\hline \multirow{2}{*}{$\mathbf{4 0}$} & Volume total Hg, $\mathrm{ml} / \mathrm{g}$ & 0,081 & 0,062 & 0,080 & 0,073 & \\
& V $_{\text {HgTotalCCA }} / \mathrm{V}_{\text {HgTotalREF }}$ & 1,000 & 0,770 & 0,990 & 0,900 & \\
& Volume Hg $\varphi \leq 50 \mathrm{~nm}, \mathrm{ml} / \mathrm{g}$ & 0,034 & 0,042 & 0,047 & 0,041 & \\
\hline
\end{tabular}

Tabela 8 - Volumes de $\mathrm{Hg}$ intrudido, a 91 dias, para concretos com $\mathrm{f}_{\mathrm{c} 28}$ de 25,30 e $40 \mathrm{MPa}$

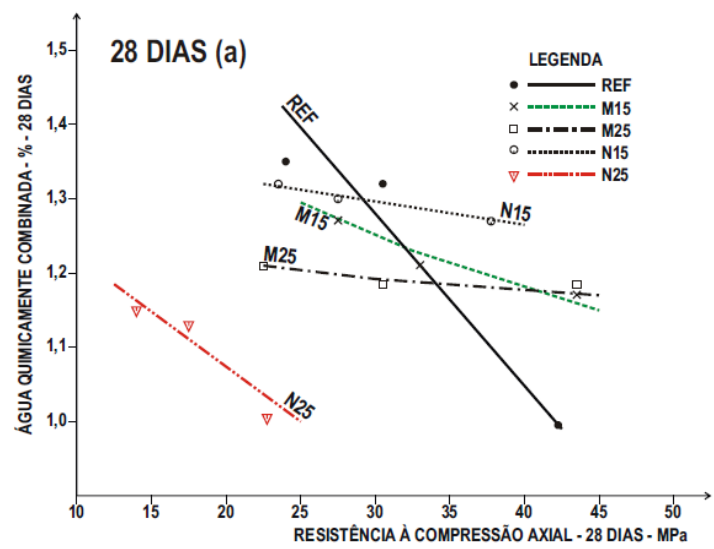

(a) 28 dias

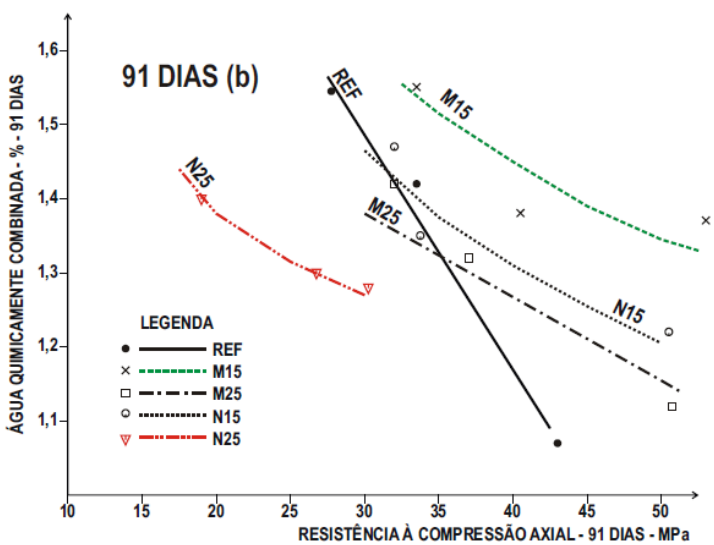

(b) 91 dias

Figura 11 - Água combinada x resistência à compressão a 28 dias (a) e a 91 dias (b)

\section{Água quimicamente combinada}

O grau de hidratação foi avaliado pelo conteúdo de água não evaporável, obtido por diferença entre temperaturas de $105^{\circ} \mathrm{C}$ e $550^{\circ} \mathrm{C}$. As Figuras 11a e $11 \mathrm{~b}$ apresentam a evolução do teor de água combinada (AC) com $\mathrm{f}_{\mathrm{c}}$ a 28 e 91 dias respectivamente.

A reta REF que representa a variação de $f_{c}$ com $\mathrm{AC}_{28}$, na Figura 11a, possui inclinação mais acentuada, indicando que o ganho de resistência se processa principalmente a partir das reações de hidratação. Para os traços M15, M25 e N15, a inclinação é menor, com tendência mais horizontal, indicando que o acréscimo de resistência se processa mais por efeito pozolânico e físico do que por reações de hidratação. $\mathrm{O}$ traço N25 encontra-se deslocado em direção de resistências mais baixas e com menor teor de AC que os demais, tendo em vista sua menor finura, que proporciona microestrutura menos compacta $\mathrm{e}$ homogênea do que o traço N15, o qual apresentou o maior teor de AC entre todos com CCA.

A Figura 11b mostra que, a 91 dias, as reações de hidratação aumentaram a inclinação da reta REF, com incremento da resistência nas relações a/mc mais baixas. Todos os traços CCAM se deslocaram em direção de resistências mais elevadas, proporcionando curvas mais inclinadas em relação às abscissas, indicando maior influência das reações de hidratação pelo aumento do teor de AC. Isso é decorrência da defloculação dos grãos de cimento pela pozolana e de sua nucleação para a formação de novos locais de hidratação. O traço M15 apresentou o valor mais elevado de AC, seguido do N15, enquanto o traço M25 mostrou menor nível de combinação, tendo em vista a maior proporção de CCAM em sua microestrutura, em decorrência da participação das reações pozolânicas junto com as de hidratação, para os mesmos níveis de resistência.

A Tabela 9 mostra que os teores de AC para CCAM foram mais baixos que o do REF para $f_{c 28-25 \mathrm{MPa}}$ e $\mathrm{f}_{\mathrm{c} 28-30 \mathrm{MPa}}$ e mais altos para $\mathrm{f}_{\mathrm{c} 28-40 \mathrm{MPa}}$, provavelmente porque, para este último, o efeito da defloculação e da nucleação da pozolana foi majorado pela maior proximidade entre as partículas dos materiais cimentícios. A 91 dias, o acréscimo de hidratação é menor para $\mathrm{f}_{\mathrm{c} 28-40 \mathrm{MPa}} \mathrm{em}$ relação a 28 dias (entre 6\% e 9\%), ocorrendo o contrário para $\mathrm{f}_{\mathrm{c} 28-25 \mathrm{MPa}}$ e $\mathrm{f}_{\mathrm{c} 28-30 \mathrm{MPa}}$ (entre $10 \%$ e $13 \%)$, com exceção do traço N25 (6\%).

$\mathrm{O}$ traço N15 apresentou os maiores teores de água combinada a 28 dias, comparados com as CCAM. 
Provável explicação para esse comportamento seria a maior disponibilidade de espaço proporcionada pelos grãos de CCAN, que apresentaram diâmetro médio superior ao dobro da cinza moída (Tabela 1), o que permitiria mais espaço para alojar produtos de hidratação.

\section{Microscopia eletrônica de varredura}

A microestrutura das pastas foi analisada por MEV com espectrômetro de dispersão de energia de raios $\mathrm{X}$ (EDS). As amostras cimentícias foram previamente metalizadas com ouro, para dotá-las de condutibilidade elétrica superficial, a fim de possibilitar a identificação dos elementos químicos principais.

\begin{tabular}{|c|c|c|c|c|c|c|}
\hline $\begin{array}{c}\mathbf{f}_{\mathbf{c} 28} \\
\text { MPa } \\
\end{array}$ & & REF & M15 & M25 & N15 & N25 \\
\hline \multirow{3}{*}{25} & A.C. 28 dias, $\%$ & 1,38 & 1,29 & 1,20 & 1,31 & 1,01 \\
\hline & $\mathrm{AC}_{\mathrm{CCA} 28} / \mathrm{AC}_{\mathrm{REF} 28}$ & 1,00 & 0,93 & 0,87 & 0,95 & 0,73 \\
\hline & A.C. 91 dias, $\%$ & 1,52 & 1,46 & 1,36 & 1,48 & 1,07 \\
\hline \multirow{3}{*}{30} & A.C. 28 dias, $\%$ & 1,26 & 1,25 & 1,19 & 1,29 & \\
\hline & $\mathrm{AC}_{\mathrm{CCA} 28} / \mathrm{AC}_{\mathrm{REF} 28}$ & 1,00 & 0,99 & 0,94 & 1,02 & \\
\hline & A.C. 91 dias, $\%$ & 1,38 & 1,41 & 1,33 & 1,42 & \\
\hline \multirow{3}{*}{40} & A.C. 28 dias, $\%$ & 1,01 & 1,18 & 1,18 & 1,26 & \\
\hline & $\mathrm{AC}_{\text {CCA28 }} / \mathrm{AC}_{\mathrm{REF} 28}$ & 1,00 & 1,17 & 1,17 & 1,25 & \\
\hline & A.C. 91 dias, $\%$ & 1,12 & 1,26 & 1,29 & 1,34 & \\
\hline
\end{tabular}

Tabela 9 - Água combinada a 28 e a 91 dias para concretos com $\mathrm{f}_{\mathrm{c} 28}$ de 25,30 e $40 \mathrm{MPa}$

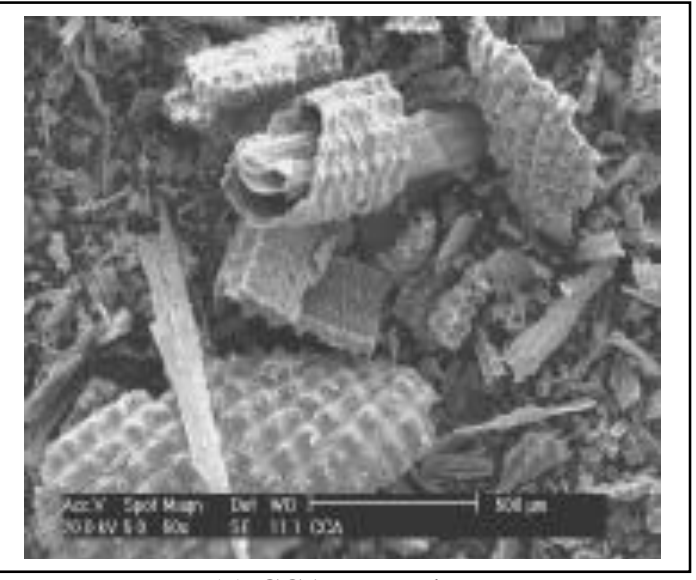

(a) CCA Natural

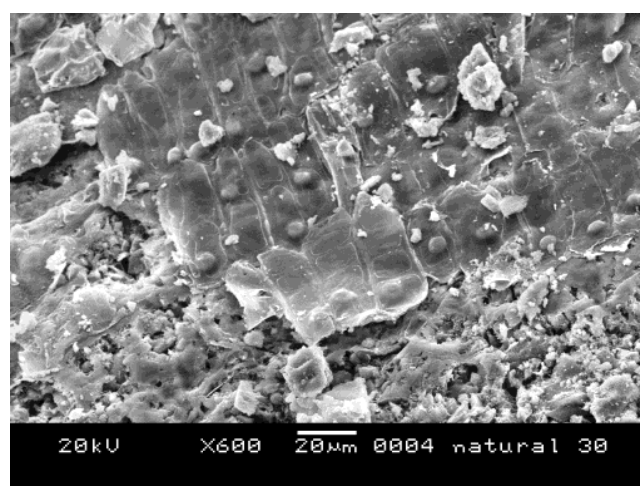

(b) CCAN
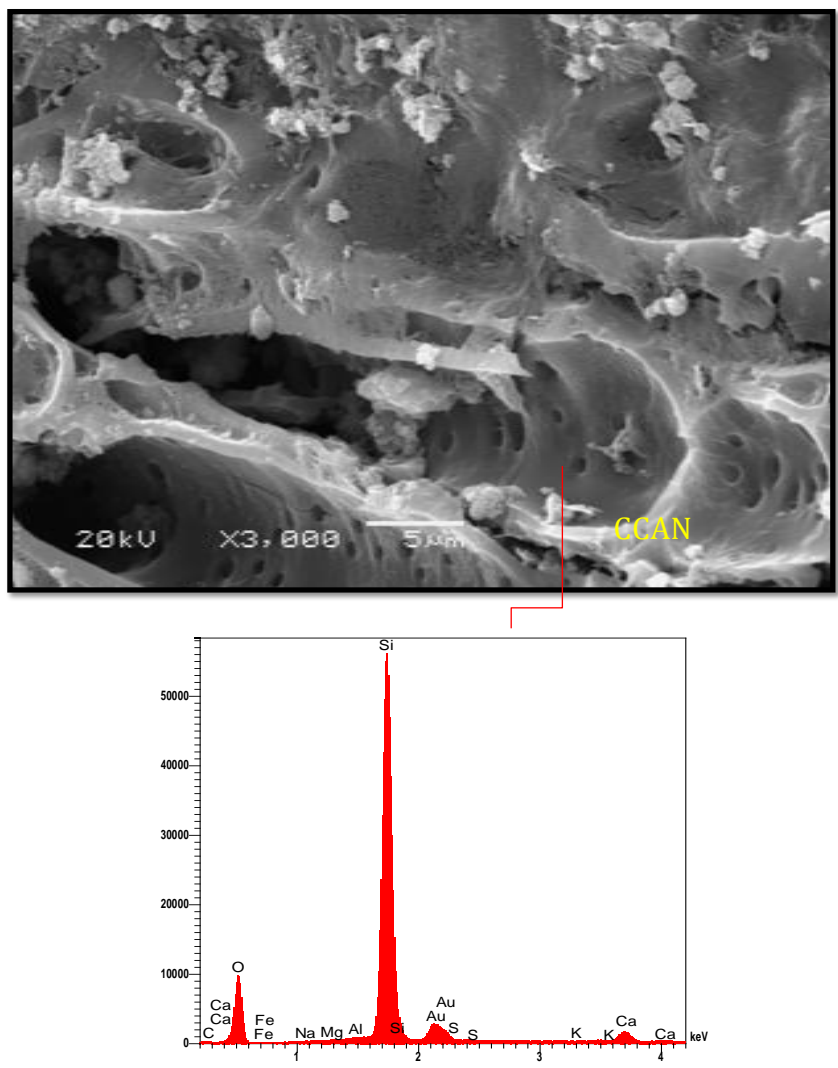

(c) CCAN

Fonte: Della et al. (2001)

Figura 12 - (a) Epidermes internas e externas de CCA natural (b) e (c) Estruturas celulares remanescentes da lignina e celulose preenchidas com produtos de hidratação e/ou pozolânicos do traço CCAN 
Segundo Amick (1982 apud DELLA, INGEBORG; HOTZA, 2001), a queima da casca de arroz produz cinzas de partículas alongadas e contorcidas, do tipo espiga de milho com epidermes internas e externas (Figura 12a), sendo sua estrutura celular e porosa proveniente da remoção da lignina e celulose na queima. Nas Figuras $12 b$ e $12 c$ observam-se essas estruturas celulares preenchidas parcialmente com produtos de hidratação e/ou pozolânicos. A análise química por EDS da Figura 14c mostra que o constituinte da epiderme interna dessa estrutura é oxigênio $(\approx$ $20 \%$ ) e silício $(\approx 75 \%)$, coincidindo com os valores obtidos por Della et al. (2001). Essa micrografia ilustra a maior porosidade que tais estruturas celulares conferem à pasta, desde que não se desfaçam totalmente se a cinza não é moída com a energia adequada.

O traço N25 (Figura 13) mostra região com grande quantidade de CCANs entrelaçadas com C-S-H em todo o perímetro, tendendo a diminuir a porosidade, porém o teor de CCAN é expressivo e grandes poros permanecem abertos com seus diâmetros originais. A relação $\mathrm{C} / \mathrm{S}$ foi baixa, em torno de 0,3, uma vez que o local analisado é região rica em sílica da CCAN. A Figura 14 apresenta o efeito de nucleação das partículas de CCAM de pequena dimensão quando comparadas com as CCAN, desde que passaram pelo processo de moagem e tiveram não apenas as partículas reduzidas como também a estrutura celular quebrada. A partir do gráfico do EDS, nota-se a formação de C-S-H de menor relação C/S.

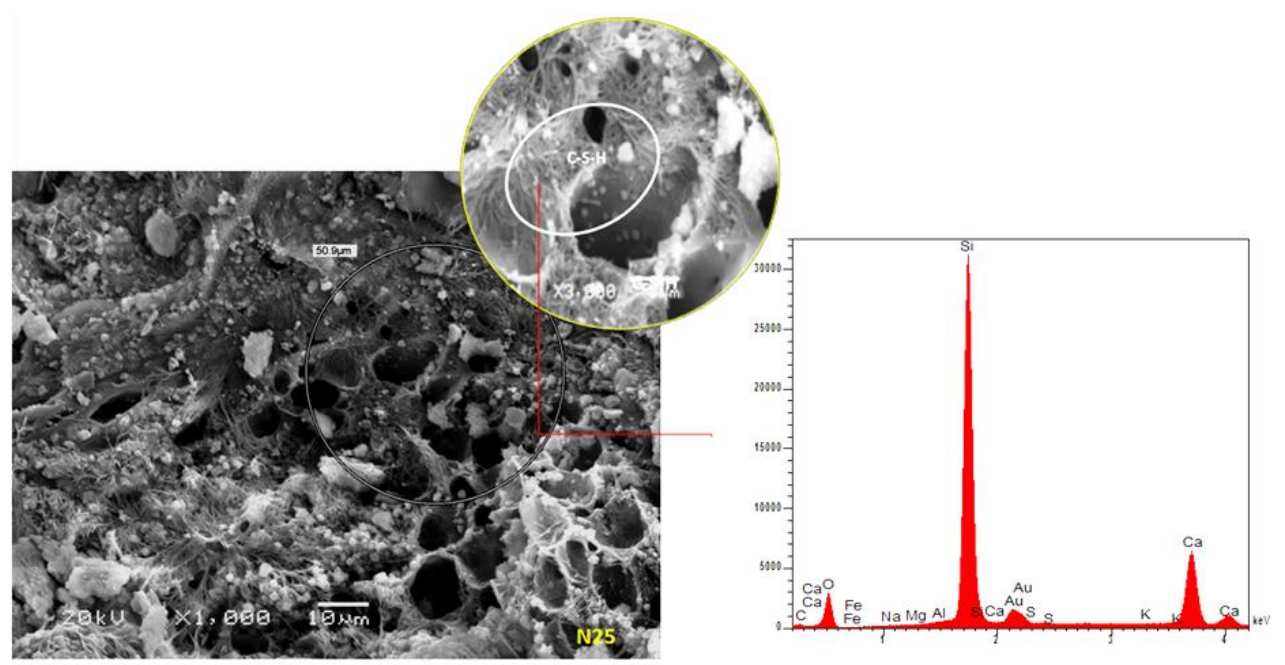

Figura 13 - MEV de traço de concreto com CCA natural

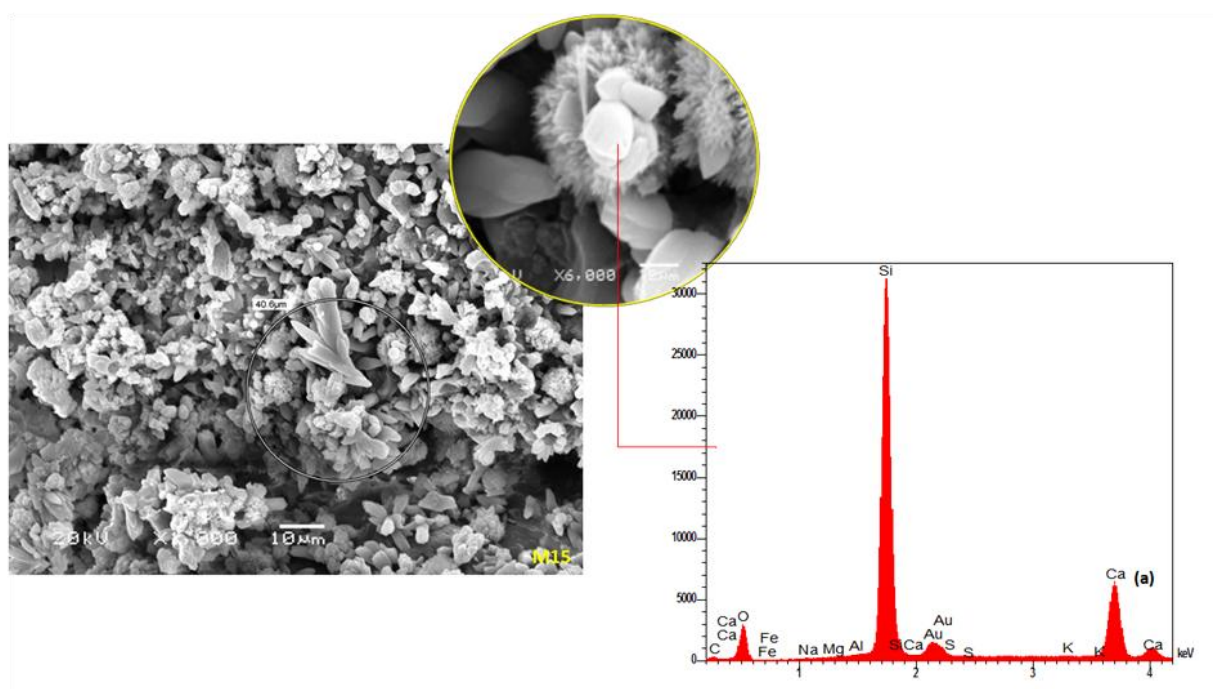

Figura 14 - MEV de traço de concreto com CCA moída 


\section{Conclusão}

O estudo de viabilidade da substituição de $15 \%$ e $25 \%$ de cimento por CCAM e CCAN em concreto estrutural apresentou as seguintes conclusões:

(a) a otimização da automoagem da CCAN na betoneira, junto com os agregados, requereu modificação da ordem de colocação dos materiais, em relação aos concretos com CCAM, e aumento do tempo de mistura de 10 min para $15 \mathrm{~min}$;

(b) as resistências à compressão axial dos traços CCAM e N15 permitiram a obtenção de níveis de resistência $25 \mathrm{MPa}, 30 \mathrm{MPa}$ e $40 \mathrm{MPa}$. Os consumos de cimento foram inferiores ao concreto de referência. As resistências dos traços N25 somente alcançaram o patamar $25 \mathrm{MPa}$ com consumo de cimento elevado, tornando-o economicamente inviável;

(c) a resistência à tração por compressão diametral e o módulo de elasticidade dos traços CCAM apresentaram valores similares ao REF, enquanto os traços N15, especialmente para $\mathrm{f}_{\mathrm{c} 28-25 \mathrm{MPa}}$, apresentaram decréscimos entre $20 \%$ e $30 \%$. A 91 dias, os traços CCAN recuperaram os mesmos patamares do concreto REF;

(d) a retração total de todos os traços com CCA foram inferiores ao REF, e os valores do traço N15 foram os menores de todos, abaixo de $0,06 \%$, limite considerado como normal para concretos convencionais;

(e) o volume total de poros do ensaio de porosimetria dos traços com CCA foram similares ao REF. Os traços com CCAM apresentaram maior volume de poros inferiores a $50 \mathrm{~nm}$ do que os CCAN, evidenciando, para os primeiros, maior refinamento devido à maior reatividade e finura. $\mathrm{O}$ traço N15 apresentou entre $10 \%$ e $20 \%$ mais de poros com $\varphi<50 \mathrm{~nm}$ do que REF, com maior teor nos $\mathrm{f}_{\mathrm{c} 28-40 \mathrm{MPa}}$ que $\mathrm{f}_{\mathrm{c} 28-25 \mathrm{MPa}}$;

(f) o teor de água combinada a 28 dias dos traços com CCA foram similares ao REF, com menos dependência do nível de resistência (curvas mais horizontais), evidenciando que seu aumento dependeu também do efeito físico dos grãos das cinzas; e

(g) as micrografias dos ensaios de MEV confirmam a maior porosidade das pastas com CCAN em virtude da manutenção da estrutura celular porosa decorrente da remoção da lignina e celulose da casca de arroz.

Os resultados desta pesquisa permitem concluir que existe viabilidade de utilização de $15 \%$ de CCAN, sem moagem, em substituição ao cimento, em concreto para fins estruturais. Os desempenhos para esse teor foram, de modo geral, um pouco mais baixos do que aqueles para misturas com CCAM ou REF, a 28 dias, entretanto ainda dentro de parâmetros considerados adequados para estruturas convencionais. O teor de $25 \%$ de CCAN não foi técnica e economicamente viável para uso em concreto.

\section{Referências}

AHMAD, S. H.; SHAH, S. P. Structural Properties of High Strength Concrete and its Implications for Precast Prestressed Concrete. PCI Journal, v. 30, n. 6, p. 92-119, 1985.

\section{AMERICAN CONCRETE INSTITUTE. ACI}

318-08: building code requirements for structural concrete and commentary. Farmington Hills. 2008.

\section{AMERICAN SOCIETY FOR TESTING}

MATERIALS. ASTM C 490-96: standard practice for use of apparatus for the determination of length change of hardened cement paste, mortar and concrete. West Conshohocken, 1996.

\section{ASSOCIAÇÃO BRASILEIRA DE NORMAS}

TÉCNICAS. NBR 5738: concreto: procedimento para moldagem e cura de corpos-de-prova. Rio de Janeiro, 2003a.

BRASILEIRA DE NORMAS TÉCNICAS. NBR 5739: concreto: ensaio de compressão de corposde-prova cilíndricos. Rio de Janeiro, 2003b.

BRASILEIRA DE NORMAS TÉCNICAS. NBR 5753: cimento portland pozolânico: determinação da pozolanicidade. Rio de Janeiro, 1992.

BRASILEIRA DE NORMAS TÉCNICAS. NBR

6118: projeto de estruturas de concreto:

Procedimento. Rio de Janeiro, 2007.

BRASILEIRA DE NORMAS TÉCNICAS. NBR

7211: agregados para concreto: especificação. Rio de Janeiro, 2005.

BRASILEIRA DE NORMAS TÉCNICAS. NBR 7215: cimento portland: determinação da resistência à compressão. Rio de Janeiro, 1996.

\section{BRASILEIRA DE NORMAS TÉCNICAS. NBR} 7222: argamassa e concreto: determinação da resistência à tração por compressão diametral de corpos-de-prova cilíndricos. Rio de Janeiro, 1994.

BRASILEIRA DE NORMAS TÉCNICAS. NBR 8522: concreto: determinação do módulo estático de elasticidade à compressão. Rio de Janeiro, 2003. 
BRASILEIRA DE NORMAS TÉCNICAS. NBR 11578: cimento portland composto. Rio de Janeiro, 1991.

\section{BRASILEIRA DE NORMAS TÉCNICAS. NBR}

12653: materiais pozolânicos. Rio de Janeiro, 1992.

BRASILEIRA DE NORMAS TÉCNICAS. NBR 12655: concreto de cimento portland: preparo, controle e recebimento: procedimento. Rio de Janeiro, 2006.

DELLA, V. P.; INGEBORG, K.; HOTZA, D. Caracterização da Cinza de Casca de Arroz para Uso como Matéria Prima na Fabricação de Refratários de Sílica. Química Nova, v. 24, n. 6, p. 778-782, 2001.

FENG, Qingge et al. Efficiency of Highly Active Rice Husk Ash on the High-Strength Concrete. In: INTERNATIONAL CONGRESS ON THE CHEMISTRY OF CEMENT, 11., 2003, Durban, África do Sul. Proceedings... Durban, África do Sul: The Cement and Concrete Institute of South Africa, 2003.

GUEDERT, L. O. Estudo da Viabilidade Técnica e Econômica do Aproveitamento da Cinza de Casca de Arroz como Material Pozolânico. 1989. Dissertação (Mestrado em Engenharia Civil) - Universidade Federal de Santa Catarina, Florianópolis, 1989.

ISAIA, G. C. Efeitos de Misturas Binárias e Ternárias de Pozolanas em Concreto de Elevado Desempenho: um estudo de durabilidade com vistas à corrosão da armadura. 1995. Tese (Doutorado em Engenharia Civil) - Escola Politécnica, Universidade de São Paulo, São Paulo, 1995.

ISAIA, G. C.; GASTALDINI, A. L. G.; MORAES, R. Physical and Pozzolanic Action of Mineral Additions on the Mechanical Strength of High-Performance Concrete. Cement and Concrete Composites, Essex, Inglaterra, v. 25, n. 1, p. 65-72, 2003.
ISAIA, G. C.; GASTALDINI, A. L. G. Critical Analysis of HPC Having High Contents of Mineral Additions, part II, mix proportion and durability. Revista IBRACON de Materiais, v. 3, p. 39-52, 2007.

MEHTA, P. K. Rice Husk Ash: a unique suplementary cementing material. In: MALHOTRA, V. M. (Ed.). Advances in Concrete Technology. Malhota, 1994. (MSL Report 94-1 (R) CANMET).

MINDESS, S.; YOUNG, J. F.; DARWIN, D. Concrete. 2. ed. Prentice Hall: Pearson Education, 2003. 664 p.

PRUDÊNCIO, L. R.; SANTOS, S.; DAFICO, D. A. In: ROCHA, J. C.; JOHN, V. M. (Ed.). Utilização de Resíduos na Construção Habitacional. Porto Alegre: Antac, 2003. (Coletânea Habitare, 4).

REGO, J. H. S. Caracterização do Resíduo Cinza de Casca de Arroz (CCA) no Brasil. In: JORNADAS SUD-AMERICANAS DE INGENIERÍA ESTRUCTURAL, 2004, MendozaArgentina. Anais... Mendoza, Argentina: Facultad de Ingeniería, Universidad Nacional de Cuyo, 2004. 1 CD-ROM.

SENSALE, G. R. Strength Development of Concrete with Rice-Husk Ash. Cement and Concrete Composites, v. 28, n. 2, p. 158-160, 2006.

SHEHATA, L. D. Deformações Instantâneas do Concreto. In: ISAIA, G. C. (Ed.) Concreto: ensino, pesquisa e realizações. São Paulo: Instituto Brasileiro do Concreto, 2005. p. 633-654.

\section{Agradecimentos}

Os autores agradecem ao CNPq-Programa PROSUL, pelo apoio financeiro para a realização desta pesquisa, e à CAPES, FAPERGS e CNPq, pelas bolsas ofertadas. 